\title{
Negotiating the search for diagnosis and healing tuberculosis in Namibia. A case study of a Ju/'hoansi speaking man.
}

\author{
Diana Gibson \\ Research in Anthropology and Sociology of Health (RASH) \\ Department of Anthropology and Sociology \\ University of the Western Cape \\ South Africa \\ E-mail:gibson.diana@gmail.com
}

\begin{abstract}
This case study of tuberculosis among Ju/'hoansi speakers in a small village in Otjodzondjupa district, Namibia, shows how different notions concerning tuberculosis and TB-like complaints become a area of uncertainty and even contention in a situation where tuberculosis education is good but diagnostics, and by extension treatment, are not always easily accessible. The paper argues that culturalism in the health services turns attention away from the socio-economic and political aspects of tuberculosis. It furthermore shows that Ju/hoansi speakers have to turn to plant medicines to deal with their ill health when the interface with the health care services become problematic. Plants are understood as standing in a particular relationship with humans and with nature as well. Yet the use of plant medicines is also a terrain of medicinal knowledge and practice contested by the health care services as potentially unsafe and counterproductive to TB treatment.
\end{abstract}

Keywords: Namibia, Ju'/hoansi, tuberculosis, diagnostics, medicines, plants, poverty

\section{Introduction}

Medicines, which include pharmaceuticals, plant medicines and materia medica, have social and cultural meaning (Reynolds Whyte et al, 2002) and are also linked to the ways in which people make sense of, and respond to, a sickness like tuberculosis; its symptoms, diagnosis and diagnostic technology and treatment (Bennstam, 2004; Greene, 2004; Harper, 2006; Ho, 2004; Jackson, 1996; Nichter, 1994; Rodriguez-Reimann et al, 2004). This paper falls within the ambit of medical anthropology and interrogates tuberculosis and medicines use - both pharmaceuticals and plant medicines - among Ju/'hoansi, or San as they are often referred to, in a remote part of Namibia. The paper shows that, because of poor access to, and/or inadequate diagnostic technology, Ju/hoansi - who 
suspect that they have tuberculosis, but are not diagnosed - have to treat themselves with local medicinal plants. We do not argue that localised ideas or 'models' of tuberculosis are in opposition to that of biomedicine, but show that biomedical diagnostics and technology are often absent or unreliable.

In Namibia tuberculosis affects a disproportionate number of Ju/'hoansi speakers who suffer and die from it each year. It is a disease that marks social inequality, lack of power and poor or insufficient nutrition. Tuberculosis is also a terrain of confusion and even of contestation, and this paper tries to unravel some of the intricacies of TB at local level. This involves the multi-faceted ways in which the diagnostics and treatment of tuberculosis is experienced, as well as the manner in which people, who suspect that they may be suffering from $t i b i^{1}$, as it is locally called, try to deal with their ill health in the absence of pharmaceutical treatment. They do so by utilising plant medicines, a practice which is frowned on by health care providers and deemed as potentially unsafe and as interfering with medicines (Chinsembu, 2009). The paper explores a number of interrelated issues:

1. The way in which datasets can 'hide' the high prevalence of tuberculosis amongst a marginalized ethnically defined group.

2. Tuberculosis as a disease of structural inadequacy. As well as the inherent 'culturalism' (Lock and Nguyen, 2010:8) of the Namibian State which stereotypes San sufferers as resistant or non-adherent because of their 'culture'.

3. The problems and misunderstandings surrounding diagnostic technology.

4. The ways in which sufferers understand and use TB medicines.

5. The use of medicinal plants in the absence of positive diagnosis.

The paper uses a case study of one man, named Dam, to illustrate the complexity of understandings and practices surrounding this disease.

\section{Methodology}

The San in Namibia and Botswana have been extensively studied by anthropologists (Biesele, 1993, 2004; Gordon, 1992; Lee ,1979; Marshall, 1976, 2000; Shostak, 1981; Suzman, 1999; Widlok, 1999; Wiesner, 2005) and films, photographs, media and other representations of them have equally been widely circulated throughout the world ${ }^{2}$ (Tomaselli, 2006; Wiesner, 2003). Yet very little anthropological research has been done in relation to tuberculosis among the San.

This study, which has been going on for three years, focused on villages of Ju/'hoansi speakers in the Tsumkwe area of Otjodzondjupa district, in north-eastern Namibia. The Tsumkwe area encompasses about $20000 \mathrm{~km}^{2}$, with a population of about $11000 \mathrm{San}$

Our earlier research indicated that local people have a variety of 'categories' of tuberculosis.

2 The John Marshall Ju' hoan Bushman Film and Video Collection is held at the Smithsonian Institution's Human Studies Film Archives and includes hundreds of hours of ethnographic film of the Ju/ hoansi (earlier called !Kung) recorded in the Kalahari between 1950 and 2000. 
people. Two villages, $\mathrm{N} / /$ hoq'ma and $\mathrm{N} \neq \mathrm{a}$-Jaqna were selected for the study. The villages are small and fairly remote, with adult populations ranging from 50 to about 120 people. There are two health facilities in the area, in the larger settlements of Tsumkwe and Mangetti Duin.

Policy documents, extant literature, as well as archival records have been scrutinised. This was triangulated with life histories, observation of, interviews and group discussions with health care providers, Directly Observed Treatment (DOTs) workers, traditional healers, and people who had tuberculosis in the past or present. All of the aforementioned, as well as the vast majority of people who had been diagnosed with TB were interviewed and observed. The research is qualitative and used observation, formal and informal interviews, individual and group discussions, case studies and photographs as focus for discussions. By compiling genealogies and by comparing these to peoples' clinic cards, we were able to trace personal histories of tuberculosis over the lifetimes of individuals in a village.

Interviews and discussions with villagers were done with the assistance of Ju/hoansi interpreters who have some high school education and who can speak both Afrikaans and English. Some of the villagers were able to speak Afrikaans and could follow the process of translation quite closely. Questions, responses, remarks and discussions were translated. Interviews and discussions were tape recorded and transcribed. Some of the activities were filmed and photographed. Informed verbal consent was obtained.

\section{Dam: a case study}

As indicated above, this paper mainly uses a case study to untangle the complexity of TB among a disadvantaged group of people in a distant village. In 2009, during research in N//hoq'ma, I took a photograph of a Ju/hoansi man, Dam. He was sitting next to the fire, drinking a decoction of infused medicinal plant roots and telling me about his past and his experiences with TB. Dam was born in Kaudom, which is now a nature conservation area. When he was a child, his family was still able to move around the countryside to forage and hunt.

As a boy, Dam contracted tuberculosis. He was sent to the distant hospital in Rundu (in Kavango region), about 200 kilometers away, where he was treated for six months. Archival records show that, at the time, hospitalisation was viewed as the best method to ensure patient adherence to treatment. It was a frightening, lonely and confusing time for the boy, Dam. A couple of years later the South African Army removed the $\mathrm{Ju} /$ 'hoansi from the Kaudom area to another village, where they were supposed to settle more permanently. Here, Dam contracted TB again, but this time around, in line with the directly observed treatment (DOTs) regimen, he was given a month's worth of medicine at a time to take with him and to drink under observation of a family member. 
The treatment continued for six months.

When we met Dam in 2008 he, as well as the majority of the adults living in the village, suspected that he had contracted tuberculosis again. He coughed, was losing weight, felt exhausted and weak at times, became feverish and his phlegm was sometimes bloody. At the time the photograph of him was taken he was drinking a decoction of sourplum (Ximenia caffra or $g / / o e h$ ), which the Ju'/hoansi often utilise to treat people who cough blood (Leffers, 2003; Gibson \& Oosthuysen, 2009). In 2008 Dam was one of the villagers whose sputum samples had been taken about three months earlier by the TB education team when they visited the area. He never found what the outcome of the tests had been. Dam's health record showed that he had been tested, but did not document the results. A couple of months later another sputum sample was taken. When the health promotion staff visited the village again, Dam enquired after his own results, and was informed that he did not have tuberculosis (TB). Early in 2009, another man from the village, Xamace, was suddenly hospitalised and died from TB. Then Dam's own boy was hospitalised and passed away as a result of TB. A family member from another village had died from Multi Drug Resistant (MDR) tuberculosis about 18 months before.

In the meantime Dam remained unwell and he was tested again in 2010. This time the results were positive and a vehicle from the closest hospital, about 80 kilometers away, was sent to fetch him to the hospital. Dam baulked. He refused to get into the vehicle, claiming that he will assuredly die in the hospital. He wanted the health care staff to give him his TB pills and to allow him to take it at home. The frustrated health care staff left and a couple of days later a hospital vehicle was once again sent to pick up Dam. He was not in the village, but had gone out to search for mangetti nuts and, if lucky enough, to hunt. The vehicle arrived again a week later. This time Dam was in the village, but still adamantly refused to go to the hospital - he was convinced that he would die there. He almost came to blows with the male nurse who insisted that Dam should be hospitalised. Dam refused to go. He wanted to take his medicines at home.

Like many villagers he had learned over time that Ju/hoansi speakers usually suffer from tuberculosis without HIV infection. He felt negated through the long and inconclusive process of diagnostics - he had after all been saying all the time that he had TB. Dam was angry and bitter that, while he had long insisted that he was sick, the health care system maintained that he was not. He felt that staff had treated him like an ignorant and fractious child and talked down to him. Dam, like most of the villagers, was also certain that the government was mostly concerned with services to and treatment of 'blacks' (people from the adjacent Kavango and Hereroland areas) who had TB in combination with HIV. Dam died five weeks later. 


\section{Databases and biopolitics}

To critically bring into focus TB among the San, it is necessary to first analyse the biopolitics of this disease in Namibia by focusing on health statistics and the national epidemiology. This requires an investigation of government policies and its collection of data sets - to calculate mortality, morbidity, infection and cure ratios and indicators. These statistics are utilised for surveillance, interventions, the implementation of prevention strategies and to curtail the spread of this infectious disease (Youde, 2008). Data sets are disaggregated along certain selected dimensions, which in turn affects which groups are targeted, what kind of interventions are done, and which issues receive most urgent attention.

At international level, statistics (concerning TB in Namibia) appear in a worldwide data-base which compares infection and rates of Directly Observed Treatment (DOTs) from individual countries in relation to the $85 \%$ treatment target rate as set out by the World Health Organization (WHO) as its international surveillance, prevention and control strategy. At face value this may seem like an example of Foucault's (1998) notion of a style of government that regulates populations through biopower. Yet, dominant State discourses and policies inadvertently function to make certain groupings, like the San (and individuals like Dam), largely 'invisible' and thus 'unregulated' and not sufficiently provided for.

According to Health Unlimited (HU), the NGO contracted by the Namibian government to run DOTs, TB education and prevention programme in the Tsumkwe area, the San are not targeted by the government as a population group for health interventions. In terms of tuberculosis statistics they are rather subsumed under the health indicators for particular regions and districts. The State health services, being under-resourced and understaffed, contracted out the primary health care promotion function regarding tuberculosis in Otjozondjupa district to $\mathrm{HU}$, but diagnostics remain the State's responsibility.

Apart from the logistical problems, the efficacy of TB tracing, prevention and control is affected by the inclusion of people with HIV/AIDS into the broad Namibian notified TB databases. Although the HIV prevalence among the San is low, among other groupings in Otjozondjupa region the co-infection of HIV/AIDS and tuberculosis is high and the prevalence of Multi-Drug Resistant tuberculosis (MDR) is rising (Sibeene, 2009). The main focus of the government is on HIV co-infection, where treatment is complicated. The target/risk groups are mostly not San and, as a result, the assumed State surveillance of the Ju/hoansi is often patchy and incomplete.

To obtain information about the prevalence of tuberculosis among the San, one has to search under the health statistics of Health Unlimited. This international NGO focuses on 'indigenous people' or 'first people'. In the Otjozondjupa district HU nevertheless 
runs programmes inclusive of the whole population of the area because, for the Namibian government, the San have no more claim to health services and interventions than the rest of the population.

Currently the HIV prevalence in Namibia is between $20-22 \%$, with about $64 \%$ of the aforementioned cases being co-infected with TB (USAID, 2009). Yet, in the case of the $\mathrm{Ju}$ /hoansi, the HIV prevalence is low at about 3\% (Lee \& Susser, 2001; Susser, 2003). Co-infection of HIV/TB is even lower. While the San make up a very small percentage of the Namibian population ( $2 \%$ of 2 million people), the prevalence of TB is nonetheless very high. Rates of more than 1500 TB cases per 100000 people have been recorded for the San- one of the highest prevalence rates in the world (Health Unlimited, 2003). According to Wiesner (2003) more than 50\% of adult deaths among the Ju/'hoansi is attributed to TB. The life expectancy for the San is approximately $22 \%$ lower than the national average and their mortality rate from TB an estimated $30 \%$ higher than the national average (Suzman, 2001). The prevalence of Multi-Drug Resistant tuberculosis is also rising among the San (Health Unlimited, 2003; Wiesner, 2003).

\section{Structural inequality and 'culturalism'}

Medical practitioner and anthropologist, Paul Farmer $(1997,1999)$ argues that there is a relationship between poverty, marginalisation and disease. Southern African research literatureaboundswithstudiesdescribingtheissuesthatperpetuatethespread oftuberculosis and give rise to its high incidence (de Beer, 1984; de Villiers, 1991; Grange and Zumla, 1999; Packard, 1989; Strebel and Seagar, 1991; Wilson and Ramphele, 1989). Such factors include overcrowding, impoverishment, poor nutrition and being members of historically disadvantaged communities (Svavamve and Ehlers, 2008; Farmer, 1999; De Beer, 1994; Packard, 1989,).

Tuberculosis is a disease that marks social inequality, lack of power and poor or insufficient nutrition. A longitudinal study by Wiesner (2003) has shown that, over time, Ju/'hoansi communities have lost access to a great deal of land and environmental resources and they often suffer periods of great financial and environmental stress and of hunger. Not surprisingly the Human Development Index for the Ju/'hoansi San is less than half the national average, while their Human Poverty Index is more than double the national average. Per capita income of the San is reportedly the lowest among all language groups in Namibia, and the majority of the population lacks access to means of earning cash income. Food insecurity, landlessness, poor access to education, extreme scarcity and dependency heightens vulnerability to TB (Suzman, 2001; Wiesner, 2003). It is difficult for impoverished and marginalized people (like the Ju/hoansi) to maintain their health. Farmer (1999) argues that it is precisely the conditions of structural inequality such as poverty, hunger, and oppression that predispose people to develop active TB. 
The San are simultaneously nationally perceived as a group which, according to a spokesperson of the Department of Health, "clings to their culture and their way of life" (Interview). They are thus often represented by the State (and the media) in a way that Lock and Nguyen (2010) refer to as a 'culturalism', i.e. as "distinct and essentialized communities in the name of the respect for differences" (Fassin and Rechtman, 2005:348). Health care providers in our study frequently referred to the 'culture' of the $\mathrm{Ju} /$ 'hoansi as problematic in relation to poverty and tuberculosis. For example, according to one health care worker the Ju/'hoansi "do not use their medicines correctly because of their culture, they believe plants can cure them (Interview). Another opined that "the San come to the hospital too late because they use their healers and take their (plant) roots" (Interview). Yet a third complained about the "backward ideas and practices" of the Ju/hoansi and linked it to the high prevalence of TB amongst them (Interview). In this way the notion that 'culture' affects patient adherence can turn attention away from the social, economic and political basis of poor health among marginalized groups. Such 'culturalism' from health care providers involves a form of "decontextualised blaming of the patient" and puts the responsibility for treatment failure on the sufferer instead of the provider; thereby ignoring the influence of poverty, discrimination, and systemic injustice (Greene, 2004: 402, 403).

Understandings of TB that do not cohere with the medical view, are perceived by health care providers as erroneous 'culture and beliefs' - which, in turn, is viewed as problematic for TB education and treatment adherence. At the same time Ju/hoansi sufferers, whether they are diagnosed with TB or suspect that they have it, interpret their signs and symptoms of ill health in the context of their own lives and circumstances as well as those of the community they live in. The San, even whilst they are portrayed in somewhat simplistic ways in the media and in institutional understanding, are not necessarily under the control of their own hegemonic "culture". They interact with, and are part of, wider national and global processes, reflect on their own lives and try to cope with ill health in a variety of ways (Lock and Nguyen, 2010:9).

\section{The ambiguity of diagnostics}

TB education for the San in Otjozondjupa is good. The health care workers are dedicated, many can speak Ju/hoansi, and local people understand their message quite well. N//hoq'ma villagers can recite the causes and warning symptoms of TB. They know a lot about TB medication, what it involves, how it must be taken, the necessity of adherence to treatment, as well as the fact that TB and plant medicines should not be used simultaneously. At any given time, there are people in the village who are on TB treatment.

When villagers talked about this disease it was apparent that knowledge and information about tuberculosis is often represented as 'hard' and uncontestable. 
For example, TB is caused by a 'bug' (mycobacterium) infection. It is curable through a strict regimen of four pharmaceuticals, which are taken for six months. There are certain factors which contribute to its spread, e.g. social circumstances, poor diet, smoking, coughing 'on' others, poor ventilation and sanitation, etcetera.

Yet, the diagnosis of TB was not straightforward. In this remote part of Namibia it is most often done through a sputum smear microscopy. Usually three sputums are taken consecutively and sent to the laboratory in Grootfontein, more than 200 kilometers away (mostly dirt road). This is the baseline test for $\mathrm{TB}$, but according to the $\mathrm{WHO}$ its reliability can be between 35-53\%. It is also the cheapest and thus most affordable test. Since there are no laboratory facilities in Tsumkwe or Mangetti, the two closest clinical facilities, Dam's sputum samples were sent to Grootfontein, and then to Windhoek. Namibia has few facilities with microscopy services or trained staff to do diagnostics (Zvavamwe, \& Ehlers, 2008). This makes it difficult to ascertain whether a patient's sputum remains directly microscopic positive $(\mathrm{DM}+\mathrm{ve})$; thereby indicating that live TB bacteria are present in the sputum, and/or whether the patient is responsive to TB treatment. A further step in diagnostics is the sputum culture, which has to be done in the capital, Windhoek, which is about 700 kilometers away. It can take from six weeks to three months for the results to return. It is also expensive. Another possibility is an $\mathrm{x}$-ray - this is done only in Grootfontein, but can also be confusing.

Thus, tuberculosis, its diagnosis and treatment is not necessarily clear-cut. TB is very much a social disease and is transmitted through interaction. In this regard research in South Africa has shown that the classic DOTs (directly observed treatment) approach, which focuses mostly on transmission and exposure between members of a household, potentially underestimates the wide circles of social relationships and interaction that people have in reality, and which exposes them to potential infection (Classen et al, 1999). Dam had visited other villages and could have been infected during this time, whilst simultaneously spreading his infection. The classic DOTs approach, however, focuses almost exclusively on 'new' infections.

In areas with high TB rates, many people are exposed to others who have infectious TB. Most of the time people who have been exposed do not develop full-blown TB. A person can also have a latent TB infection and accordingly has bacteria in his body, whilst remaining symptom free. In such a case the infection can only be detected through certain tests, e.g. a skin test, which is not so easily accessible in remote areas in Namibia. If an $\mathrm{x}$-ray is taken, it will seem 'normal' (Temple et al, 2008).

Studies have also shown that TB recurs quite a lot, sometimes within 1-2 years, in people, like Dam, who had earlier been 'cured' of TB. This can be due to poor adherence, treatment failure or reinfection - the latter is defined as "a recurrent TB episode in which the strains of the separate episodes differed by more than four bands" (Verver et al, 2005: 1430). TB infection is thus not single event. According to Marais et al (2009:1):

In settings in which TB is endemic, the first infection is likely to occur in childhood 
but is unlikely to be a single lifetime event. In all likelihood, ongoing TB transmission within endemic communities causes repeated episodes of infection... results from recent molecular epidemiologic studies challenge the unitary concept of TB pathogenesis by providing definitive evidence that reinfection contributes substantially to the global TB disease burden. Studies using IS6110 fingerprinting have established that most infections causing active $\mathrm{TB}$ in adults from $\mathrm{TB}$-endemic areas represent currently circulating strains that were recently transmitted, most often outside of the household. Studies also have shown that more than $50 \%$ of recurrent disease occurring in endemic settings results from reinfection.

The Namibinan national DOTs strategy prioritises people with pulmonary TB, since they can infect others. Yet, a person who has been cured, can still have pockets of TB bacteria which can become isolated in organs of the body, and which can, if a person's immune system declines, become active again. It is also possible to have TB of the glands, heart or another body part. Such cases are difficult to identify and diagnose and they may go untreated.

The experience of people like Dam was that it can take a long time to be diagnosed and to get started on treatment. Tuberculosis control programmes focus their efforts on patients with newly diagnosed $\mathrm{TB}$, who are responsible for most of the disease burden. However, compared with new TB cases, people who have a history of TB (both disease episodes and treatment), like Dam, experience poorer treatment outcomes and a higher mortality rate. A person can also become infected with multiple strains of Mycobacterium tuberculosis (Richardson et al, 2002).

\section{Pharmaceuticals}

Tuberculosis treatment protocols are long in duration, involve a complex schedule, and can have side effects long after the initial symptoms of the disease have disappeared. (Greene, 2004: 402). What Dam did not understand, and the health care worker did not explain, was that people who have recurring TB are, in accordance with WHO guidelines, usually hospitalised for two months. This is because their treatment regimen also changes. According to a health care provider they usually receive Streptomycin injections for two months, as well as the four standard pharmaceuticals - Isoniazid, Ethambutol, Rifampicin, and Pyrazinamide. Then they go on a one month regimen of the latter four. Afterwards they continue for five to six months with Rifampicin, Isoniazid, and Ethambutol. The treatment regimen is accordingly much longer and more complicated than Dam had experienced in the past (Sonnenberg et al, 2009).

It is important to also consider the way in which the daily experiences of using TB medication, as well as its side-effects are understood. Many people find the idea of continuously taking treatment for subclinical disease difficult to accept 
(Jackson, 1996). Sufferers might feel that the side-effects like of TB medication, like nausea, vomiting, fatigue, insomnia, discoloured urine, peripheral neuropathy and such, make them feel worse or might interpret it as indicative of another illness. Research has shown that, as a result, sufferers often adjust their dosages, the timing of the doses or discontinue treatment (Ibid; Shimada et al, 1995). Dam, however, had during his first two bouts of $\mathrm{TB}$, strictly adhered to his treatment regimens. He was not averse to the pharmaceuticals - he resisted hospitalisation. He was also disillusioned about the fact that, whilst he maintained that he had TB, his disease remained medically unrecognised.

When Ju/hoansi suspect that they have $\mathrm{TB}$, but are undiagnosed, they search for other forms of treatment, e.g. they use medicinal plants - like Dam did. At this point I wish to turn to the aforementioned photograph of Dam next to the fire, drinking a medicinal plant. Since Dam, as well as his wife, family members and local healers (n/um kxaosi or owners of $\mathrm{n} / \mathrm{um}$ - healing power) suspected that he had TB, he was treated with a variety of plants over time. This aspect will be discussed more fully in the next section.

\section{Plant medicines}

According to Chinsembu (2009) the use of African traditional medicines (ATM) is a contested terrain in Namibia. Although ATMs are utilised extensively in resourcepoor settings, this practice is largely discouraged by staff working in health prevention and care programmes. It is believed that ATM can negatively affect the efficacy of pharmaceuticals, e.g. TB medication, or it may lead to discontinuation of treatment. Many Ju/hoansi used medicinal plants to take care of their ailments, especially if they had no pills. Like pharmaceuticals, medicinal plants are imbued with meaning and form part of local healing knowledge and practices. Unlike pills, medicinal plants are 'alive' and part of the environment (Gibson \& Oosthuysen, 2009).

It is of interest that, like most plant medicines, the aforementioned sourplum, is usually taken fresh from the veld. According to healers ( $n / u m$ kxaosi interviewed, the plant material is 'wet' and has healing/ spiritual power or energy called $n / u m$. Plant medicines were used for different kinds of ailments, and depending on whether they were available in the area or not. N/um has to be heated up, but also has to be both given (by a healer or family member) and taken (by the sick person). N/um is shared (Gibson, \& Oosthuysen, 2009). N/um kxaosi, who were observed, sometimes talked to the plants, either when collecting them, or during or after administering them. In interviews they stressed that the plants had to be 'thanked' and 'paid' for their sharing of $n / u m$. Plants, humans, animals, insects, the sky, the soil, rain, wind etc. are part of nature (Tsi or !ou). Thus, whereas pills are objects, medicinal plants are much more. They have spirit or essence and are linked or entangled through the movement of máq - air, breath, wind, 
energy and vitality - between them, over time and through space (Low, 2009). Nani, an old and experienced healer tried to explain:

When you walk, you leave a spoor (a trail), animals leave a spoor, rain leaves a spoor... you can see from the spoor what kind of rain was falling, hard rain, soft rain. Even plants leave a spoor - the grass drags on the ground, it falls in places, the seed falls, it rolls, the leaves, fall and blow around. You can see it was there. You leave a spoor and the leaves or the grass or seeds, they blow over it, then you can see you shared that story, that place even long after(wards). The máq moves between us, we share it. Plants are alive, they have a power to live, they change the soil around them, they can affect animals, they protect themselves from humans from animals, they move their seeds, they can trek (migrate) to other places and grow there.

It would seem that plants have "power to grow themselves and be alive" (Rival \& McKey, 2008:12), and arguably a certain 'agentivity' in relation to themselves (Barad, 2007:44; Rival\& McKey, 2008). Study participants stressed that plants breathe, live, reproduce, feed, poison, defend against or hide themselves from predators. They 'drink', 'eat' and move in the air. They can travel across distance; can affect the environment, the kind of animals that may live there etc. Plants can be stronger or weaker, depending on where they grow. Through the movement and sharing of máq, i.e. essence/wind/ air, people, animals and plants interpenetrate and transform each other. Ultimately plant medicines are utilised because people like Dam are in distress and in need of relief.

It was possible to identify a number of plants that were used to treat suspected TB. Both Leffers (2003) and Leger (1997) have also recorded plant use among the $\mathrm{Ju} /$ 'hoansi, but they did not explore the way in which plant medicines, efficacy or safety was understood. The latter two aspects, as well as the possibility of an adverse reaction between plant medicines and pharmaceuticals used to treat TB, are the main reason for the concern of health care providers. From study observations it seems that healers are, however, careful about the plants utilised and that they have their own understanding of efficacy. When a healer ( $n / u m$ kxao) prepared an infusion of roots of the Horn pod tree (Diplorhynchus condylocarpum) for Dam, the former also drank some of the infusion, saying that it helped to prevent TB infection as well. It could thus be used as a prophylaxis. Dam drank the infusion in the morning and evening for two consecutive days, after which his symptoms disappeared. He started coughing again five days later. Once again he was given an infusion and the symptoms disappeared for two weeks. Mouse-eared combretum (Combretum heroroense) and African wattle (Peltophorum africanum) was also utilised over time to treat Dam. According to healers other plants used to treat TB-like symptoms include the camelthorn (Acacia erioloba), Bloodwood (Pterocarpus angolensis) and lavender tree (Heteropyxis natalensis). If symptoms disappeared for some time, the plant was perceived to be efficacious. While plants could be efficacious because of a placebo effect, some of them have also been found to have antimicrobial and/ or antiinflammatory components (Green et al, 2010; Theo et al, 2009; van Vuuren, 2008). 
Healers insisted that the treatment of each sick person had to be handled on an individual basis. They were certain the plants they used were safe because many healers before them had used it over time (Gibson, \& Oosthuysen, 2009). The use of plant medicines was learned from other healers and such knowledge was transmitted orally. Xau, a healer, said sometimes the spirits showed him a new plant to use in his dreams. Whilst he was very familiar with the environment, and knew whether animals ate it; he tested it with his tongue for possible toxicity and drank the decoction himself. Xau's guidelines for safety were roughly the following: he broke the roots, leaves or bark (depending on how he was going to use it), rubbed it on his skin and even inside of his mouth. Sometimes he tested a 'new' remedy with his tongue and waited for a while. He chewed the plant and swallowed some of it. If it did not taste burny, astringent or bitter and/or he did not experience adverse effects within a day or so, he assumed that the plant was safe. If a plant did not seem to work, another one, which could be used for the same illness or for similar symptoms, was tried.

Some of the plants mentioned by the healers for TB treatment have been studied in other African countries and found to have anti-bacterial and anti-inflammatory properties (Green et al, 2010; McGaw et al, 2001; Okeleye et al, 2010). This indicates that more emphasis is needed on research on plants and plant material and its efficacy in TB treatment, especially since Africa does not have enough medicines in general and even a relatively well-resourced country like Namibia has pockets of acute infection, in this case by TB and MDR TB which is not directly linked to HIV/AIDS.

\section{Conclusions}

One of the aims of this paper was to illustrate how an overstretched health care system inadvertently contributes to the problem of tuberculosis because it is not always possible to diagnose, supply drugs, and counsel patients: this leaves them with little insight into the complexities of this disease and its treatment and without the necessary pharmaceuticals to do so. At the same time, the Namibian government cannot give higher priority to the San in relation to the rest of the population.

The paper explored tuberculosis in a small group among whom co-infection with $\mathrm{HIV}$ is low, whilst the government has to provide services for a wider population within which the opposite is true. Although the health system is geared to providing equal access and tries to display an equitable approach to testing for, diagnosing and dispensing treatment to some two million inhabitants across a vast land surface area; it means in actuality that the access to diagnosis, and thus treatment, is not equal for the already marginalised.

At the same time, the embeddeness of culturalism in the health care system diverts attention from the social, economic and political relationships with poor health. As most $\mathrm{Ju} /$ 'hoansi speakers report, they are easily blamed for their poor TB outcomes. Ju/'hoansi 
patients are often held responsible when their TB treatment fails or when they develop resistance to TB drugs. Culturalism thus affects health outcomes and end up confusing, exasperating and even antagonising the sick.

In the absence of diagnosis local people turn to medicinal plants to treat their symptoms, yet this practice is frowned on and perceived as a form of 'cultural' undermining of the tenets of good medical practice, and in particular as subverting TB treatment. Nonetheless, some of the plants utilised by the healers and locals for TB treatment have been studied elsewhere and found to have anti-bacterial and antiinflammatory properties. Healers also have their own understandings of efficacy and of safety in relation to plat medicines. This indicates that more emphasis is needed on research on plants and plant material and its efficacy in TB treatment, especially since Africa does not have enough medicines in general and even a relatively well-resourced country like Namibia has pockets of acute infection, in this case by TB and MDR TB which is not directly linked to HIV/AIDS.

\section{References}

Barad, K., 2007, Meeting the universe halfway. Quantum physics and the entanglement of matter and meaning. Durham: Duke University Press.

Beyers, N., 1999, Impact of social interactions in the community on the transmission of tuberculosis in a high incidence area. Thorax, 54, pp.136-140.

Biesele, M., 1993, Women like meat: The folklore and foraging ideology of the Kalahari Ju/'hoan. Bloomington: Indiana University Press.

Biesele, M., 2004, Speaking truth to a powerful film: engaging with a representation of an indigenous people. Anthropology News, 8-9.

Chinsembu, K., 2009, Model and experiences of initiating collaboration with traditional healers in validation of ethnomedicines for HIV/AIDS in Namibia. Journal of Ethnobiology and Ethnomedicine 2009, 5:30.

Classen, C., Warren, R., Richardson, M., Hauman, J., Gie, R., Ellis, J., van Helden, P., De Villiers, S., 1991. Tuberculosis in anthropological perspective. South African Journal of Ethnology, 14, p. 69.

Farmer. P., 1999, Infections and inequalities. The modern plagues. Berkeley: University of California Press.

Farmer, P., 1997, Social scientists and the new Tuberculosis. Social Science and Medicine 44, 3, pp 347-358.

Fassin, D., Rechtman, R., 2005, An anthropological hybrid: The pragmatic arrangement of universalism and culturalism in French mental health. Transcultural Psychiatry, 42, 3, pp.347-366.

Foucault, M., 1998, The Will to Knowledge, The History of Sexuality Volume 1, Hurley, R., trans., Penguin Books, Great Britain. 
Gibson, D \& Oosthuysen, E., 2009, Between N!atxam and tibi. A case study of tuberculosis and the Ju/honi in the Tsumkwe region, Namibia. Anthropology Southern Africa, 32, 1\&2, pp. 27-36.

Gordon, R., 1992, The Bushman myth. The making of a Namibian underclass. Boulder, San Francisco and Oxford: Westview Press.

Grange,J and Zumla, A., 1999. Tuberculosis and the poverty-disease cycle. Journal of the Royal Society of Medicine, 92(3): 105-107.

Green, E., Samie, A., Obi, .M., Bessong, P., Ndip R., 2010, Inhibitory properties of selected South African medicinal plants against Mycobacterium tuberculosis. Journal of Ethnopharmacology, 130, 1, pp.151-7.

Greene, J., 2004. An ethnography of nonadherence: Culture, poverty and tuberculosis in Urban Bolivia. Culture, Medicine and Psychiatry, 28,3,401, pp.401-425.

Health Unlimited., 2003, Indigenous peoples. Health Issues. Summary of presentation at indigenous peoples and socioeconomic rights expert workshop. March 20th-21 ${ }^{\text {st }}$. Available on http://www.cpsu.org.uk/downloads/Health\%20 Issues.pdf. Accessed 13/02/07.

Lee, R., 1979, The !Kung San. Men, women and work in a foraging society. Cambridge: Cambridge University Press.Lee, R. 1993, The Dobe Ju/Hoansi (Case Studies in Cultural Anthropology). New Orlando Florida: Harcourt (2 $2^{\text {nd }}$ edition).

Lee, R., Biesele, M and R. Hitchcock (Eds.), 2002, The Kalahari San: SelfDetermination in the Desert. Cultural Survival Quarterly, 26, 1, pp.1-60.

Lee, R. and Susser, I., 2002, Confounding conventional wisdom: Women's power and low HIVIAIDS rates among the Ju/ hoansi of Namibia and Botswana. Paper presented at the XIV International AIDS Conference in Barcelona.

Leffers, A., 2003, Gemsbok bean E' Kalahari truffle. Traditional plant use by Ju/'hoansi in North-Eastern Namibia. Windhoek: Gamsberg Macmillan.

Leger, S., 1997, The hidden gifts of nature. A description of today's use of plants in West Bushmanland. Windhoek: ded, German Development Service Lock, M. And Nguyen, V., 2010, An anthropology of biomedicine. Malden, MA: Wiley-Blackwell.

Low, C., 2009, Khoisan Medicine in History and Practice, Research in Khoisan Studies Volume 20, Koln: Rüdiger Köppe Verlag.

Marais, B., Pareker, S., Verver, S., van Rie, R. and R. Warren., 2009, Primary and Postprimary or Reactivation Tuberculosis: Time to Revise Confusing Terminology? American Journal of Roentology, 192 W198. Available online. http://www.ajronline.org/cgi/content/full/192/4/W198. Accessed 18/08/2010.

Marshall, L., 1976, The !Kung of Naye Naye. London: Cambridge University Press. Marshall, L ., 2000, Nyae Nyae!Kung Beliefs and Rites.Cambridge MA: Peabody 
Museum Press.

McGaw, L., Rabe,T., Sparg, S., Jäger, A., Eloff, J., van Staden, J., 2001.

An investigation on the biological activity of Combretum species. Journal of Ethnopharmacology, 75, 1, pp. 45-50.

Okeleye, B., A. Samie, A., Bessong, O., Mkwetshana, N., Green, E., Clarke, A. and R. Ndip., 2010. Crude ethyl acetate extract of the stem bark of Peltophorum africanum (Sond, Fabaceae) possessing in vitro inhibitory and bactericidal activity against clinical isolates of Helicobacter pylori. Journal of Medicinal Plants Research,. 4, 14, pp. 1432-1440.

Richardson, M., Carroll, N., Engelke, E., van der Spuy, G., Salker, F., Munch, Z., Gie, R., Warren, R., Beyers, N. and P. van Helden., 2002, Multiple Mycobacterium tuberculosis Strains in Early Cultures from Patients in a High-Incidence Community Setting. Journal of Clinical Microbiology,40, 8, pp. 2750-2754.

Rival, L., McKey, L., 2008, Domestication and diversity in Manioc (Manihot esculenta Crantz ssp. esculenta, Euphorbiaceae) . Current Anthropology ,49, 6, pp.1119-1128.

Susser, I., 2003, Ju/hoansi survival in the face of HIV: Questions of poverty and gender. Anthropologica, 45: 120-128.

Sibeene, P., 2008, Namibia: Drug Resistant TB Strain Confirmed. New Era, $16^{\text {th }}$ May. Available on http://allafrica.com/stories/200805160540.html.

Accessed 18/06/2008.

Shostak M., 1981, Nisa. The life and words of a !Kung woman. London: Allen Lane Sonnenberg, P. Murray, J. Shearer, S., Glynn, J., Kambashi, B. GodffreyFauset, P., 2000, Tuberculosis treatment failure and drug resistancesame strain or reinfection? Tropical Medicine E̋ Hygiene. 94, 6, pp.603607.

Susser, I., 2003, Ju/hoansi survival in the face of HIV: Questions of poverty and gender. Anthropologica, 45, 1, pp.121-128. Suzman, J. 1999.

"Things from the Bush". A contermporary history of the Omaheke Bushmen. Klosterberg: Schlettwein Publishing.

Suzman, J., 2001, An Introduction to the Regional Assessment of the Status of the San in Southern Africa. Windhoek, Namibia: Legal Assistance Center. 